\title{
INVESTIGACIONES
}

\section{LA ESCUELA COMO ESPACIO DE CIUDADANÍA}

\author{
The School As Space Of Citizenship
}

\author{
A Escola como Espaço de Formação Cidadania
}

\author{
Silvia Redon Pantoja \\ Escuela de Pedagogía - Facultad de Filosofía y Educación - Pontificia Universidad Católica de Valparaíso \\ Chile - silvia.redon@ucv.cl; Fonos: 56-32.2274345 - 56-32-2274343
}

\begin{abstract}
RESUMEN
La investigación ${ }^{1}$ que se presenta, expone los resultados de las representaciones de ciudadanía que construyen niños y niñas de 4 a 10 años de edad, en discursos y acciones en el espacio escolar. Para ello se utilizó un diseño de estudios de caso instrumental y múltiple, que permitió entrar en profundidad en la escuela, a través de los discursos, observaciones y documentos en cada caso: ocho escuelas de distintas administraciones y localidades rurales y urbanas. Los análisis, permitieron levantar categorías en tres grandes matrices: La alteridad, el sentido de lo común, y la identidad como eje que configura a las demás y que a su vez es determinado por ellas. Lo común se presenta como una categoría debilitada, tanto desde la experiencia y significación de los estudiantes así como de los docentes. Ambos coinciden en sus discursos, en representar la sociedad desde la transacción instrumental mercantil, en el cual ellos actúan como ciudadanos electores de bienes. En suma, se observa un déficit de lo social para configurar el sentido de lo "común", en los niños/niñas, determinado, entre otros, por el contexto, la procedencia social, la edad y por la mediación débil realizada por los docentes.
\end{abstract}

Palabras clave: escuela, ciudadanía, docentes, niños y niñas.

\begin{abstract}
His research presented, realizes the results obtained with regard to the representations of citizenship built children aged 4 to 10 speeches and actions in the school space. This instrumental and multiple case which allowed us to go into depth in the social life of school space, through speeches, comments and documents in each study cases studies design was used: eight schools of various administrations and rural and urban locations. Records of observation, interviews and analysis of documents, allowed us to lift categories in three large arrays: the otherness, the meaning of the ordinary, and finally, identity as axis set to others, and which in turn is determined by them. Usually occurs as a weakened category, both from the experience and significance of students as well as teachers. Two match in his speeches to represent society from the commercial instrumental transaction in which they act as voters citizens of goods. In short, notes a social deficit to configure the meaning of the "ordinary", in the male/ female, determined by pop-up experience context, social origin, age, and by the weak mediation by teachers.
\end{abstract}

Keys words: school, citizenship, Children, Teachers.

\section{RESUMO}

O trabalho de pesquisa apresentado, reflete os resultados obtidos no que diz respeito às representações de cidadania construídas por crianças de 4-10 anos de idade, através de discursos e ações no ambiente escolar. Foi utilizado um estudo de caso e vários instrumentos, que nos permitiu entrar profundamente na vida social do espaço escolar, através de discursos, argumentos e documentos em cada estudo de caso: oito escolas de diferentes autoridades e localidades rurais e urbanas.

1 La investigación que se expone en este artículo corresponde al Proyecto de investigación financiado por CONICYT-FONDECYT de iniciación No 11070100: "La escuela como espacio de formación ciudadana". Las representaciones simbólicas en la Infancia. 
Registros de observação, entrevistas e análise documental, permitiu-nos levantar três matrizes principais categorias: A alteridade, o sentido da corrente, e, finalmente, a identidade como um eixo que faz os outros e que, por sua vez é determinada pela elas. Normalmente apresenta-se como uma categoria enfraquecida, ambos a partir da experiência e do significado de alunos e professores. Ambos concordam em seus discursos, para representar a sociedade instrumental da transação comercial em que eles agem como cidadãos eleitores real. Em suma, há uma falta de social para definir o significado de "comum" no masculino / feminino, determinado, entre outros, a mediação da experiência emergente do contexto de fundo social, idade e fracos realizado pelos professores.

Palavras-chave: escola: pública, professores, meninos e meninas.

\section{ANTECEDENTES}

En la mayoría de los países latinoamericanos y de la comunidad europea, la importancia de la escuela como espacio de transmisión de valores, formación para la ciudadanía y lugar público institucionalizado en el que se debiera aprender a vivir en democracia, es tema clave de nuestra era actual. La tarea de los ciudadanos por construir espacios que nos devuelvan la esperanza del protagonismo civil, para movilizar sociedades más justas y democráticas, ubica a la escuela en el centro de los "dardos" como eje sustantivo de formación para la ciudadanía. Desde este contexto, vale preguntarse ¿qué significa construir ciudadanía en la escuela? ¿Cómo la escuela logra dar protagonismo participativo y democrático al alumnado de 4 a 10 años de edad, para que ejerza sus derechos y deberes ciudadanos? ¿Cómo el docente configura a este ciudadano/a infante? La importancia por indagar para comprender y re-interpretar el espacio en común hecho espacio civil, político y cultural que la escuela debe anidar, forjar y desarrollar, son el cimiento en el cual se asienta esta investigación. ¿Qué piensan los niños y niñas de su condición de sujeto de derechos en el espacio escolar? ¿Qué imaginarios construyen de la vida colectiva en la que están inmersos la mayor parte de su tiempo-vital? ¿Qué subyace en los docentes ante el concepto de infancia, sujeto niño/a y como los re-conocen en el ámbito del Derecho? ¿Qué cultura construye la escuela como espacio de formación ciudadana? ¿Es el centro escolar el espacio público de la vivencia de la ciudadanía? Si entendemos el Centro escolar como cultura de agencia de simbolización y subjetivación; de asociatividad asegurada por la institucionalidad obligatoria de Deber y Derecho público, de vivencia de la identidad y la alteridad, implica un proyecto educativo complejo. Martínez Rodríguez ${ }^{2}$, explica cómo aumentan peligrosamente en los centros escolares, las distancias y los desencuentros entre profesorado, familias y alumnado, instalados en reproches, culpabilizaciones y exigencias recíprocas impertinentes. Cómo los derechos de cada sector se lanzan sobre los "otros" limitando las posibilidades de intervención de todos. Desde este contexto de

2 Este tema se amplía y se aborda en el texto “Construir la Ciudadanía en la Escuela” el que analiza con profundidad al centro escolar como un microcosmos de la realidad con la responsabilidad de reinterpretar el nuevo orden social en el espacio civil, político y cultural que le compete a la escuela. También aborda las temáticas de las relaciones entre familia y profesorado, aprendizaje y alumnado, relaciones de miedos y amenazas, autenticidad y luchas. El tema de los DDHH, la inclusión de la Diversidad, el problema de la desigualdad, la importancia del protagonismo infantil, la vivencia de los derechos-deberes civiles en la escuela, la vivencia de la democracia, las diferentes condiciones, formas, sentidos, políticas de participación. El currículum como negociación y sitio de poder: Aprender a negociar contenidos, valores, intereses, y promover la resolución de los conflictos son ejes temáticos desarrollados en este libro que han iluminado las reflexiones de este apartado, realizado por Martínez Rodríguez. 
conceptualizaciones, indagar socio-antropológicamente en la esfera de los significados de los niños y niñas en el espacio escolar como construcción de ciudadanía son ejes y temas relevantes de la investigación educativa, en que se ha indagado preferentemente en el sector de adolescentes y no en la infancia como lo propone este estudio.

Desde otros análisis, la cultura escolar ${ }^{3}$ entendida como el conjunto de prácticas y simbolizaciones construidas en la escuela, se encuentra hoy afectada predominantemente por el cruce de dos culturas; una asociada al tradicionalismo controlador reproducido por el propio sistema educativo y otra emergente vinculada a la cultura social que promueve un individualismo que repercute en la forma de mirar a los otros y al mundo guiada por una lógica que instrumentaliza las relaciones humanas, debilitando con ello, el sentido público en los sujetos. La cultura social afecta también a otras instituciones que impactan el itinerario simbólico que se construye en la escuela, lo cual redunda en la necesidad por indagar en los marcos éticos políticos y teórico-epistemológicos que se encuentren presentes en las representaciones y concepciones de los actores involucrados en el espacio escolar. La Comisión Nacional de Formación Ciudadana ${ }^{4}$ en Chile, alcanzó el convencimiento que la vida cívica se encuentra expuesta hoy día a un conjunto de transformaciones y cambios que afectan los fundamentos de la confianza básica y la unidad afectiva de la Nación. Esta Comisión piensa que nuestras sociedades necesitan generar en sus miembros un sentido de lealtad en cuyo cultivo la educación tiene un papel insustituible. Una sociedad democrática vigorosa y atenta, necesita desarrollar en sus miembros la idea que se trata de un proyecto común, que los compromete a todos en su presente, recogiendo la memoria histórica y mirando hacia un futuro común. La Comisión cree necesario recordar que el sistema escolar, es la institución mediante la cual la sociedad perpetúa su propia existencia. Es la encargada de la reproducción, de una generación a otra, de su "conciencia moral", formada por los sentimientos y creencias que la cohesionan y sin las cuales las lealtades más básicas de la vida social sobre las que reposa la ciudadanía son difíciles de alcanzar. ${ }^{5}$

La constitución de la escuela pública, como corolario de las acciones de importantes movimientos socio-políticos a mitad del siglo pasado, consideró la formación de ciudadanía, como una demanda pública que bajo el alero del estado nación, contribuyó a socializar

3 Ver el concepto y el cruce de 5 culturas propuesto por el autor en" la cultura escolar en la sociedad neoliberal, trabajado con profundidad por Angel Pérez Gómez.

4 Se expone con profundidad este tema en el Informe comisión ciudadana, coordinado y liderado por Carlos Peña.

5 La Comisión pudo constatar diferencias entre el currículum prescrito y las prácticas en el aula, entre lo esperado y lo que el sistema escolar efectivamente logra. Estas diferencias derivan de la diversidad de proyectos educativos; de la grave desigualdad de recursos que todavía exhibe nuestro sistema escolar; de la falta de apropiación del currículum por parte de los profesores; y de las deficiencias que subsisten en la formación de los docentes por parte de las instituciones de educación superior. En este último aspecto, nuestra investigación cobra relevancia, sustento y pertinencia a las demandas de la formación de pedagogos en las competencias de la formación ciudadana y su impacto en la construcción de sociedad.

En definitiva, los miembros de la Comisión sugieren que la educación no debe olvidar que las disposiciones más exigentes, como la de la ciudadanía, reposan y se apoyan sobre el desarrollo de virtudes más simples y más elementales. El respeto por las instituciones públicas, pero, al mismo tiempo, el desarrollo de un hábito reflexivo y crítico hacia ellas, sólo puede ser alcanzado si se cultiva el respeto al maestro, a los procedimientos de la escuela y al diálogo. 
principios básicos de vida cívica para contribuir a la cohesión política. Sin embargo, en nuestra sociedad actual, esta idea de "escuela" heredada de la Ilustración conducente a forjar la identidad de un ciudadano y su comunidad, así como su poder institucional, se han debilitado ante la aparición de una escuela oferente de "servicios" a potenciales clientes. ${ }^{6}$ Esto se vincula con la vivencia de lo político en el contexto del mercado en el que los votos se compran y se venden en la lógica de votantes consumidores por satisfacer sus necesidades, pensando la política como: "Un remedo del mercado en que los votantes son consumidores, los votos dinero y los políticos comerciantes que venden un servicio más o menos intangible. Pero las comunidades políticas no se construyen ni gobiernan de esta manera. Los países requieren ciudadanos más o menos virtuosos, capaces de tener lealtades entre ellos y dispuestos a cumplir las reglas. Y nada de eso se logra, o se explica, cuando concebimos la política como un simple intercambio" (Peña: 2007).

En este escenario, la necesidad por re-pensar el valor de la escuela como espacio de construcción de ciudadanía y la responsabilidad que le compete a los docentes, se vuelve una urgencia de nuestros tiempos, pues los temas contingentes de "igualdad versus desarrollo económico", protagonismo versus pasividad en torno a qué significa elegir, optar, comprar, son elementos sustantivos del ejercicio ciudadano. La atención "explosiva" en el tema de la ciudadanía se explica desde el actual contexto histórico, político, económico y social que arrastra del fin de milenio pasado los grandes hitos de transformaciones políticas, económicas, tecnológicas, sociales, que entre otros, se vinculan con la caída de los regimenes comunistas en Europa ${ }^{7}$, la restitución de la democracia en América latina, la configuración hegemónica de las grandes potencias sobre el planeta, entendiendo por grandes potencias, no sólo a los estados o conglomerados de estados, sino a las transnacionales comerciales, que actúan como súper-potencias mundiales que influyen en la autonomía de los estados más vulnerables, débiles y en vías de desarrollo, lo que amerita "aprender" a vivir en una "nueva democracia" ya sea porque era inexistente en el pasado, o por que hay nuevos desafíos y presiones futuras que implican un mayor conocimiento de la sociedad civil con respecto a sus derechos y responsabilidades.

El concepto de ciudadanía parece integrar las exigencias de justicia y de pertenencia comunitaria, que son respectivamente los conceptos centrales de la filosofía política de los años ochenta, en donde el actual concepto da cuenta de la unión entre la idea de los derechos individuales y la noción de vínculo con una comunidad particular. El componente ético ideológico estará siempre presente a la hora de referirse a la formación ciudadana, imbricado a los procesos de socialización y rol que a la educación le toca jugar en la sociedad, para formar ciudadanos democráticos, sujetos de derechos-deberes, vigilantes

6 Precisamente, la racionalidad imperante en el currículo técnico, viene a exacerbar las dificultades para la construcción de una ciudadanía, al enfatizar el eje económico productivo de la formación remitiendo los contenidos éticos y culturales exclusivamente al ámbito privado de la existencia, entendido como un espacio disociado de lo público. Por su parte, el informe Delors, propone una educación para una ciudadanía crítica e intercultural que debe "dar a cada persona la capacidad de participar activamente, durante toda la vida en un proyecto de sociedad”, asegurando que tal capacidad pueda ser ejercida por todos y todas, sea cual sea su origen social, económico o cultural (Delors: 1996; 65).

7 En la segunda mitad del siglo pasado (1960) no hubiéramos imaginado a Rusia y a China "negociando" con EE.UU. y portando en el bolsillo del pantalón un teléfono que es computador, que se conecta al satélite y que pesa menos que la billetera. 
de su entorno, éticamente responsables, capaces de reconocer al otro como un legítimo otro, tolerantes, no discriminadores y respetuosos de la diversidad social y cultural, es así que la formación ciudadana se transforma entonces en pilar fundamental de la calidad de la educación. Ciudadanía, Democracia y educación, son así, pilares fundamentales que se entrelazan y dependen el uno del otro, es decir, el ciudadano requiere de la democracia para hacerse ciudadano y la democracia requiere de ciudadanos para no volverse en una "pantomima" o máscara de participación; y por otro lado la educación a través de su currículum debe "ciudadanizar" la política y "politizar" la ciudadanía. Esto implica, sin duda, rescatar a la "escuela-encapsulada" de los muros de las aulas, alejada de la vida social y personal, aspectos que podríamos llamar las estrategias de formación ciudadana, esto es, la formación de una cultura política ciudadana como procesos educativos que hay que singularizar.

En Latinoamérica, el concepto de ciudadanía ha cobrado vigencia política y social, tras la crisis de la Soberanía nacional, sobre la base de la cual la educación se ha constituido en el campo cultural, donde conceptos como democracia e identidad del sujeto cobran vida en el concepto de ciudadanía (Osorio, j.:1993; Ottone, e, 1993; Alfaro: 1994; 1995; Leal: 1995) y en donde las cualidades y aptitudes ciudadanas son, simultáneamente, las herramientas de control y cambio social. "La manera como la corrupción ha ido expandiéndose en diversos escenarios de la vida cotidiana de la sociedad y en el manejo de lo público es sin duda uno de los factores más erosionantes de la democracia en América Latina y que también se reproduce lamentablemente al interior de las escuelas..." (Sime Poma; Tincopa Calle; 2004).

En el ultimo tiempo, en que predominan los sistemas democráticos y en que las "libertades" adquieren un tenor de principio regulador de las relaciones interpersonales; paradojalmente, el capital cívico y asociativo se encuentra debilitado en su conocimiento, valoración y ejercicio, debido a múltiples factores entre los cuales podemos mencionar; el impacto que generó la caída de los socialismos reales en el descrédito de las utopías; la pérdida de espacios participativos en el marco de los gobiernos dictatoriales en América Latina; y la consolidación de un sistema neoliberal como único referente interpretativo de la convivencia, sustentado en un individualismo excluyente que contribuye a generar una tensión permanente entre liberalismo y comunitarismo. Se agrega además, en el contexto globalizador, el desdibujamiento del Estado como un ente regulador y representativo de la ciudadanía, al subordinar la política al poder hegemónico del mercado. ${ }^{8}$

$8 \quad$ Nuestra era posmoderna propicia la emergencia de este anhelo, ya que es en el contexto global de interconexión tecnológico, económico y político, en que estos cambios se vuelven mas evidentes debido a; la caída del muro de Berlín, el establecimiento de regímenes democráticos especialmente en nuestro continente latinoamericano y una gradual reacción crítica ante la "tensión" entre comunitarismo y liberalismo, especialmente centrada en su origen en los Estados Unidos. Esta realidad contextual o socio-histórica sitúa al currículum de formación docente y los procesos educativos en todos los niveles, en la necesidad de abordar esta competencia en los futuros profesionales de la educación y por ende en los niños/as, jóvenes del un país.

Por su parte, la caída de los regimenes comunistas en Europa, la restitución de la democracia en América latina, la configuración hegemónica de las grandes potencias sobre el planeta, entendiendo por grandes potencias, no sólo a los estados o conglomerados de estados, sino a las transnacionales comerciales, que actúan como súperpotencias mundiales que influyen en la autonomía de los estados más vulnerables, débiles y subdesarrollados; todo este contexto amerita "aprender" a vivir en una nueva "Democracia" ya sea porque era inexistente en el pasado, o por que hay nuevos desafíos y presiones futuras que implican un mayor conocimiento de la sociedad civil con respecto a sus derechos y responsabilidades. 
En este marco, la ciudadanía debilitada se ha vuelto un referente para las políticas educativas. En particular, en nuestro país, una vez recuperada la Democracia, el tema ha adquirido relevancia, al emerger discusiones que aluden al pasado cercano y las violaciones a los derechos humanos, así como, problemas relacionados con fenómenos de desterritorialización, y las transformaciones de los agentes básicos de socialización (Escuela, familia y estado), los que redundan en una falta de sentimiento de pertenencia y de identidad colectiva. ${ }^{9}$ Más aún, cuando la globalización mediática transfiere desde la simbolización marcos de conocimiento y formas de relación intersubjetiva que propenden a la "invisibilización del otro/a" y la "desconfianza del otro/a" debilitando los vínculos y prácticas asociadas a la convivencia democrática (Magendzo, 2004).

Esta consideración se vuelve relevante si se analiza a la luz de estudios internacionales de cívica que ubican a los niños y niñas chilenos por debajo del promedio en torno al conocimiento vinculado a la dimensión ciudadana. Cabe destacar, por otra parte, que las investigaciones chilenas evidencian ausencia de conocimientos vinculados al tema así como, un desencantamiento y cinismo asociado a lo político, de carácter progresivo, a medida que se acercan a la adolescencia y la juventud. Se agrega además una vivencia de los futuros jóvenes, quienes insertos en lógicas mediáticas e inmediatistas, tienden a no comprender la trascendencia de la actividad parlamentaria debido a la subvaloración subyacente de la discusión argumentativa reflexiva con fines públicos y/o comunes. El estado de la cuestión evidencia la existencia de un territorio compartido en el cual se articulan los significados de Educación, Democracia y Ciudadanía. Dicha convergencia abierta a una permanente construcción, se actualiza en los sujetos que, gracias a la intención explicita de la educación y la pedagogía, en su compromiso democrático, permite configurar un sujeto conciente de sus derechos ciudadanos. ${ }^{10}$ “...La Comisión cree necesario recordar que el sistema escolar, es la institución mediante la cual la sociedad perpetúa su propia existencia. Es la encargada de la reproducción, de una generación a otra, de su "conciencia moral", formada por los sentimientos y creencias que la cohesionan y sin las cuales las lealtades más básicas de la vida social sobre las que reposa la ciudadanía son dificiles de alcanzar. Es este conjunto de principios, sugiere la Comisión, los que han de guiar tanto el análisis de las actuales prácticas curriculares, como el diseño de las orientaciones para su mejora...” (Peña, 2004).

\subsection{INVESTIGACIONES NACIONALES E INTERNACIONALES}

En nuestro país el Ministerio de educación, el PIIE y algunas Universidades han estado investigando en torno al tema (Egaña, Cerda, Magendzo, Santa Cruz y

\footnotetext{
Ver informes de PNUD.

10 Touraine, ha afirmado que "En el momento actual en grandes partes del continente, en reuniones se discute el tema de la democracia. Hoy en todos los países se suele discutir el tema de la democracia y en muchos países escuché que la palabra democracia es una palabra sucia, sombría, contradictoria. Por tanto no es evidente hablar de democracia, pues no es para todos un concepto que evoca algo "maravilloso". Hoy en gobiernos democráticos se vive la desigualdad social con más fuerza que nunca en América Latina, la pobreza, la exclusión, la des-igualdad, con fuertes ejes de poder impenetrables por la ciudadanía y el sentido político de la democracia. Trascripción ponencia. Aula magna de la Universidad de Valparaíso-Chile. Noviembre 2004.
} 
Varas; 2004) en el entendido que, es pertinente mirar desde una nueva perspectiva las acciones docentes y sus vínculos con los valores y prácticas democráticas en la escuela. Al respecto conviene destacar los resultados de investigaciones que indican una debilidad en la aproximación al concepto de ciudadanía, la que se explica entre otras razones por la persistencia de un Currículo de enfoque técnico que, conjugado con otros factores de orden contextual y social cultural redundan en una deficiente aproximación y valoración del concepto. ${ }^{11}$ En la cultura escolar, se ha evidenciado un debilitamiento de prácticas que aluden a procedimientos democráticos, en particular, actividades vinculadas a la toma de decisiones por el alumnado, y su participación en la vida política escolar. Se ha producido una subvaloración de los contextos en que se desarrollan los consejos de curso, las elecciones de los centros de alumnos, etc ${ }^{12}$ Situación que viene a evidenciar una debilidad en el conocimiento y dimensiones que puede alcanzar el ejercicio de la vida cívica como parte de la cultura escolar, exacerbado en el tramo de la infancia. Esto queda de manifiesto en el análisis producto de investigaciones desarrolladas en nuestra universidad: "Contradicciones y Paradojas en la educación Parvularia: Un estudio etnográfico (Alvarado, Bustamante, Rubio, Tapia; 2002), utilizó un diseño cualitativo, descriptivo e interpretativo, que contempló registros de observación y análisis del discurso de "diarios docentes" a educadores en proceso de formación. Además se contempló en la unidad de estudio, grupos de discusión de Educadoras de párvulos, abarcando una población de diversos actores, discursos y realidades de observación. Los resultados arrojaron categorías vinculadas con: ausencia de la educadora en sala, ausencia de actividades pedagógicas, tendencia a un interés personal de "comodidad", atropello y abuso de poder por parte del adulto reflejado en castigos, amedrentaciones y agresiones hacia los niños/as para mantener el "control de grupo" y disciplina en la sala. "Entre el lenguaje y las imágenes de la cultura de empresa, la ciudadanía se representa como un asunto completamente privatizado cuyo objetivo es producir individuos interesados únicamente en ellos mismos y que sólo se preocupan por lograr su propio beneficio material e ideológico. Al convertir los asuntos sociales en materias estrictamente individuales o económicas, la cultura de empresa consigue ampliamente anular los impulsos democráticos y las prácticas de la sociedad civil al menospreciarlas o al absorber sus impulsos mediante la lógica de mercado..”. (Giroux, 2001: 47).

Según los países que participaron en el estudio de la IEA: 2000 (International Association for the Evaluation of Educational Achievement) plantea que la educación cívica, para que incorpore la complejidad actual del ejercicio de la ciudadanía, debe ser multidisciplinaria, participativa, interactiva, relacionada con la vida, llevada a cabo en un ambiente no autoritario, enterada de los desafíos de la diversidad social y con

11 De la investigación arriba mencionada se encuentran artículos publicados en RIIE; POLIS; BABEL: Redón Silvia, Rubio Graciela (2006) "Ciudadanía y Formación docente: sobre el concepto de ciudadanía. conocimiento y valoración en la acción pedagógica": "sujeto y Pedagogía. ciudadanía y formación docente".

12 Ver cita 12. La investigación se centra en un estudio de campo realizado en 4 escuelas básicas de en sectores populares de la Región Metropolitana, con docentes de 5 y 6 año. Estas observaciones fueron complementadas con análisis del discurso producto de entrevistas y grupos focales. 
la colaboración de los padres y la comunidad, junto a la escuela. Además asume que todo el currículo, la sala de clases, la vida cotidiana en la escuela y el clima de ésta deben estar integrados a estos objetivos.

Paralelamente, en la cultura social nacional, se ha evidenciado que Chile está bajo el promedio de América Latina en términos de adhesión a la democracia. En efecto, los datos de Latinobarómetro señalan que en el año 2002 dicha adhesión alcanzaba al 56\% de la población, cifra que descendió al 50\% según el informe del PNUD 2004. Como señalan Huneeus y Maldonado (2003) esta tendencia comportamental es preocupante y adquiere una gran importancia analítica ya que, para que la Democracia sea percibida de un modo eficaz y real por los sujetos en contextos de crecimiento económico, es fundamental que los ciudadanos se beneficien de sus resultados. Es necesario que exista una percepción subjetiva de los progresos reflejados en los indicadores objetivos. Los logros de nuestro país han sido espectaculares en muchos sentidos -y así lo pone de manifiesto la evidencia empírica- pero, pensamos, hay un déficit al que la sociedad debe hacer frente: no se ha logrado construir una identidad del país en el que hoy día vivimos, que sea lo suficientemente fuerte como para dejar atrás la nostalgia por la imagen del país pasado, esa imagen que prevaleció durante buena parte del siglo 20 y que se sostenía en el respaldo del grupo o la colectividad, en la protección del Estado, en un mercado interno protegido, en una élite ilustrada y en una democracia muy institucionalizada pero escasamente participativa (Peña, 2004).

En el contexto internacional, también han aparecido voces críticas respecto de cuáles deben ser los objetivos que debe perseguir la educación en el mundo global, en particular, se cuestiona la tendencia que se ha impuesto de entender como objetivo predominante de la educación, el desarrollo de sujetos económicamente eficientes. “...Podemos referirnos a este proceso de tecnificación como" la industrialización de la educación”. Este proceso tiende a conducir hacia un modo industrial de producción de personas educadas, que están bien preparadas para entrar en el mercado del trabajo, y en el que las tasas de entrada y salida, la estandarización, la eficiencia y la economía, se convierten en los principios rectores. En un ambiente así, los alumnos se convierten en objetos sujetos a un proceso estandarizado denominado educación" (Vonk en Biddle, Good y Goodson, 2000; 24) Los estudios ${ }^{13}$ coinciden en centrar su mirada en la escuela, intentando indagar en la cultura escolar, la vivencia de la democracia como expresión ciudadana de los escolares. Se valida la escuela como un contexto privilegiado para el desarrollo de una "común-unidad", como espacio de construcción de "significados" éticos, por antonomasia.

13 Los estudios de investigación financiado por el CIDE España 1998, titulado: "la salud democrática en la escuela" originaron múltiples producciones teóricas que centran el análisis en la cultura escolar contrastando la hipótesis de la "ausencia de la ciudadanía en la escuela".Esta ausencia se debe a la carencia conceptual de vivir la escuela como espacio público político y democrático en el que el sujeto crea y recrea en la relación con los otros, la posibilidad social de su desarrollo autónomo. 


\section{METODOLOGIA}

\subsection{EPISTEMOLOGIA EN LA QUE SE ASIENTA EL ESTUDIO}

La metodología utilizada en esta investigación se encuentra inmersa en un paradigma epistemológico cualitativo-hermenéutico que investiga las representaciones sociales de los sujetos a través de sus discursos y acciones, que se expresan en las prácticas del espacio escolar en relación a la ciudadanía.

\subsection{OBJETIVOS DE GENERAL DE LA INVESTIGACION}

Caracterizar apropiaciones conceptuales, valores y prácticas presentes en los discursos y acciones de niños/as de 4 a 10 años de edad y actores de la comunidad educativa con respecto a la escuela como espacio de formación ciudadana.

\subsection{OBJETIVOS ESPECIFICOS}

- Conocer los elementos constitutivos de los significados de los valores democráticos presentes en los discursos de los niños/as.

- Reconocer los elementos y los modos de configuración de lo público y su relación con la subjetividad presentes en los discurso de los niños/as.

- Conocer las líneas discursivas básicas que configuran el concepto de infancia y analizar los significados que subyacen en su representación en docentes y apoderados de la comunidad escolar.

- Proponer líneas de acción que faciliten el espacio escolar como formación para ciudadanía en la Infancia.

\subsection{DISEÑO}

“...Los estudios de casos son adecuados para un análisis intensivo y profundo de uno o pocos ejemplos de ciertos fenómenos;..”. (Goetz, LeCompte, 1988; 69). Según Elliot (1994), las relaciones se iluminan mediante la descripción concreta, de realidades sociales y personales en vez de a través de leyes causales y de correlaciones estadísticas. Los estudios de casos proporcionan una teoría naturalista de la situación, que en esta investigación, pretende aportar a nuestro país en un tema tan relevante como lo es, la vivencia y configuración de ciudadanía en la escuela. Los estudios de caso que se utilizan en este diseño, también se podrían denominar, del tipo "caso instrumental” y “colectivo”, que denomina Stake (1999), al referirse a un caso en el cual la finalidad del estudio no es comprender el caso en sí mismo, como lo sería un estudio de casos intrínsico, en esta investigación nos interesa el caso como un medio instrumental para comprender la problemática de la responsabilidad en la formación de ciudadanos/as en el sector de la Infancia. 


\subsubsection{Criterios en la selección de los centros}

Al trabajar con la esfera de los significados y el análisis del discurso, los "lugares de habla" determinan la contextualización de los discursos, variables como: la edad, el género, los niveles socio-económicos, los lugares geográficos en un país de características muy disímiles en sus aspectos eco-sistémicos, naturales-climáticos conlleva a itinerarios de vida cotidiana diversos. A la vez, los contextos urbanos o rurales de las escuelas podrían configuran distintas representaciones en los niños y niñas según su emerger de "habla-situada" y por tanto, imaginarios simbólicos de lo público, lo común, y la vivencia de ciudadanía en la escuela, importante de considerar a la hora de cruzar las matrices de estas variables en el análisis del discurso y la cultura escolar. Desde estos antecedentes, se considerarán ocho centros, con los siguientes criterios de selección que explican y sitúan los contextos de habla desde la dimensión:

a. Nivel socioeconómico: los niveles socioeconómicos, bajos, medios-bajos, y medios-altos, determinados por la administración corporativa educacional del país en colegios públicos que concentran a una población tendiente de clase baja; colegios subvencionados que concentran una población de clase media y media-baja y colegios particulares pagados que concentran clases medias y medias-altas.

b. Contexto urbano y rural.

\section{PRESENTACION RESULTADOS INVESTIGACION}

Los resultados se corresponden a diferentes procesos analíticos producto de la graduación en la información recogida por los registros de observación, los análisis de los documentos y el análisis de los discursos tanto de entrevistas clásicas y formales como espontáneas y "fotos-memoria" que fueron especialmente utilizada para los niños y niñas más pequeños. Es importante señalar que la mirada se focalizó en las interacciones de los niños y niñas, con sus pares y docentes en la institución escolar, no como cultura del currículum con toda su complejidad y múltiples elementos, sino focalizada en las relaciones al espacio físico, la normatividad desde el sentido de pertenencia y la red vincular entre pares y docentes. Las categorías emergen desde: Formas de relación con los docentes (aula); Formas de relación con la escuela; Formas de relación entre pares. Estos diferentes ámbitos relacionales, configuran una primera categorización que se traduce en el Cuadro 1 en la página siguiente.

Luego de estas categorías libres, producto de los primeros procesos analíticos de indexación sin conexión con árboles categoriales, vale decir, vinculada a líneas discursivas básicas en las diferentes fuentes de información, se procedió en una segunda fase analítica, que conecta estas categorías con los ejes temáticos otorgados por la discusión teórica y problemática de investigación. 
Cuadro 1

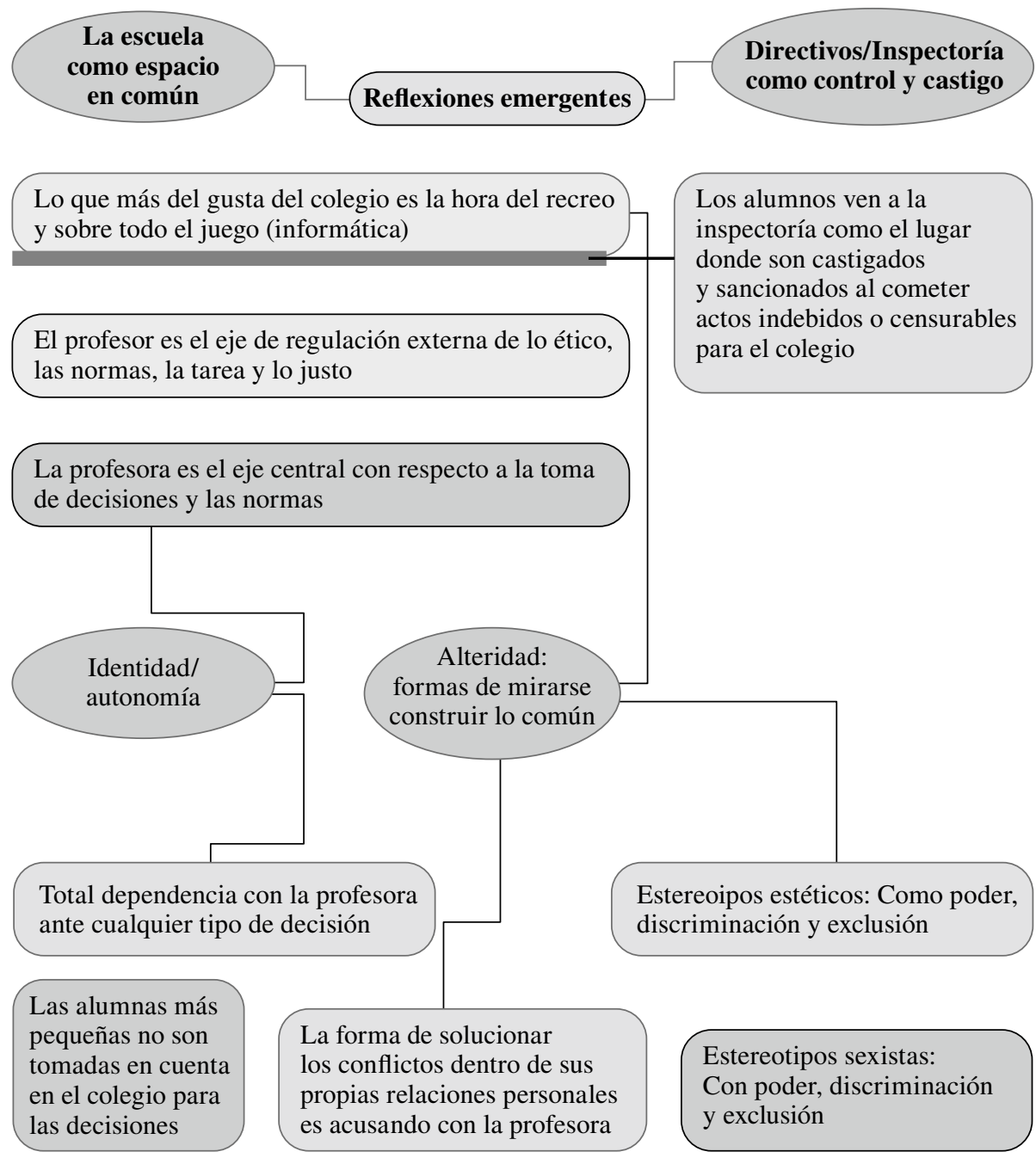

3.1. En la matriz de alteridad, se encuentran las categoría vinculadas a las relaciones que configura el sujeto, con el "otro/a" o lo otro: los pares, los docentes los medios, y el impacto de esta relaciones en la configuración de sujeto. La primera indagación se vinculó con:

3.1.1. Los "medios televisivos"14. Se recogió información masiva a través de encuestas con respecto a lo que hacen niños y niñas al llegar a casa, otorgando a la TV y juegos

14 Los cuadros específicos que contiene la información de frecuencia de tiempo ante el TV, programas con más alta demanda por niños y niñas, cuadro general con respecto a los programas que los niños y niñas observan se encuentra en el informe in-extenso de esta investigación. 


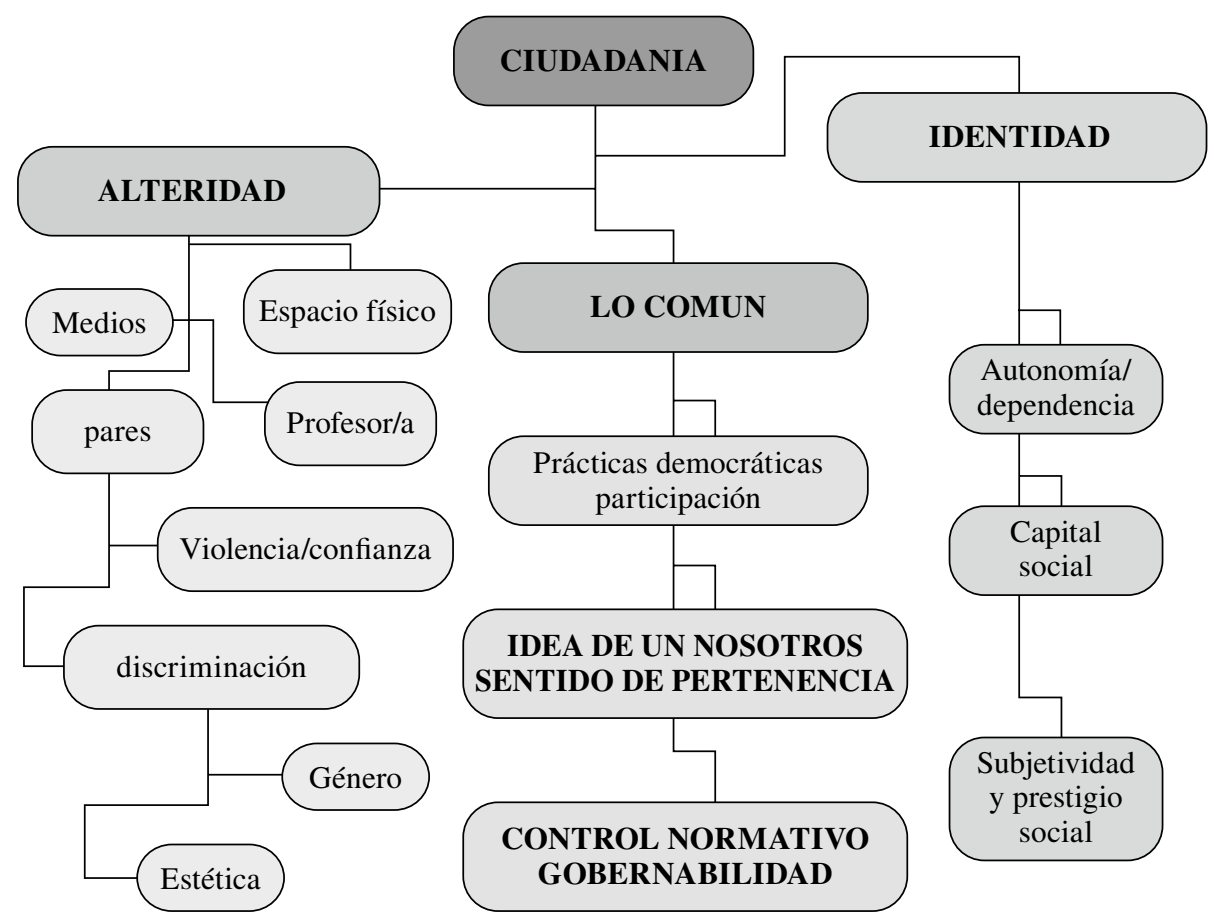

informáticos la supremacía en la utilización del tiempo, compartida con tareas escolares y en algunos casos, el juego de barrio o vecindad. Estas características están diferenciadas por edad y por clase. En las escuelas públicas, el barrio y la calle ocupan un espacio para la recreación, en reducido porcentaje, en el caso rural, la red vincular con parientes es significativa, sin embargo se impone en todos los niños y niñas, el mayor tiempo dedicado a mirar TV y juegos informáticos. Esta indagación masiva descriptiva (encuestas) nos permitió conocer el itinerario cotidiano de los informantes. Con las respuestas se pudo conocer la cantidad de tiempo que destinan a este medio de comunicación masivo, qué tipo de programación prefieren y como podría repercutir en los juegos y las características en estilos de trato, formas de asociarse y compartir el espacio en común.

3.1.2. Relación profesor estudiante. Esta categoría se construye con registros de observación y análisis de discursos vinculados específicamente al aula. Se observa en la relación profesor/a estudiante, una tendencia de relación asimétrica, mediatizada por el poder y el control ejercido por el adulto, quien ordena y hace cumplir las normas, especialmente las que dicen relación con el "orden" establecido por la escuela.

"Técnico: Vengan para acá. Si no se forman, se quedan sin patio mañana. ¿Orinaron y se lavaron las manos?

Niños: No. 
Técnico: ¿Qué esperan? vayan a orinar y lavarse. Ya!! a formarse en la fila o se quedan sin patio. Cállense, se sientan y se callan o si no se van al lado”.

(Caso 3, Registro 8).

"Profesora: Vamos inmediatamente a una guía que tenemos acá. Quiero que saquen el cuaderno de lenguaje en la página 68, 68, 68 y ahí vamos a poner arriba tarea, póngalo ahí, tarea, mañana no quiero que vaya a llegar nadie sin la tarea, eso si, porque o si no se va a quedar sin recreo".

(Caso 3, Registro No 28).

“(Los niños tocan la flauta). Profesor: ¿Alguien les dijo que tocaran? Cuando yo diga... Sin tocar, sólo pongan los dedos”.

(Caso 3, Registro No 34).

De más de 120 registros de observación, la mayoría de estos son referidos al tema de imposición de normas y casi la totalidad se dan en esta dinámica de autoritarismo y sin sentidos. Re-configurando a este sujeto que construye su subjetividad desde los otros y lo otro, se le observa inmerso en una pasividad de decisiones, en las que en el espacio de recreo, se siente protagonista según sean los mecanismos de prestigio social y pertenencia que luego se analizará en la categoría respectiva. Los medios le ofrecen estereotipos sociales especialmente en la gran demanda de teleseries observadas, en las que no tienen la opción de decidir, reflexionar, actuar y forjarse como sujetos constructores de lo social y por ende personal.

3.1.3. Relación entre niños y niñas. Esta categoría se sustenta en registros de observación y entrevistas grupales e individuales en las que transitan líneas discursivas y acciones relacionada con las formas de relación entre pares. En este eje surgen las sub-categorías de Discriminación en dimensiones de género y estética y violencia versus confianza. A lo largo de la investigación se pudo constatar que dentro de los centros educativos la dinámica frente a este tema es la siguiente: los niños y niñas que se encuentran en grupos pequeños de amigos cercanos son muy leales entre ellos, dándose una dinámica de compañerismo recíproco, pero en grupos de mayor cantidad de niños, donde las relaciones no se dan desde la cercanía y los afectos, los niños acostumbran a manifestar bajos niveles de tolerancia y frente a cualquier rose con sus pares, las reacciones más comunes se expresan desde las descalificaciones e insultos, hasta los golpes. Esto se da más comúnmente en los cursos superiores (de $3^{\circ}, 4^{\circ}$ y $5^{\circ}$ Básico).

Niño 1: Profe, ¿Hay que escribirlo?

Niño 2: No, tonto estúpido”.

(Caso 2, Registro No 25).

Niña (Sexto básico): Que te pasa fea culiá, ¿Por qué te metiste en esa wea? Hocicona.

(Le tira el pelo a la niña de cuarto y viceversa)

Niña: iisuéltame, suéltame!!! 
Profesor: Mírenlas y eso que son primas”.

(Caso 2, Registro $\mathrm{N}^{\mathrm{o}}$ 7).

Niño: Aquí todos tienen sobrenombres.

Entrevistadora: ¿Cómo se dicen?

Niño: Papiche.

Entrevistadora: ¿Por qué?

Niña 1: También le decimos tumor.

Niño 2: A esta le dicen tetas de goma y tetorin.

Niña 1: A él le dicen momia, a esta pocas pecas o cara de challa, paradero de moscas. A ese le dicen tomate".

(Caso 2, Registro $\mathrm{N}^{\circ}$ 6).

Entrevistadora: ¿Te sientes respetado por tus compañeros?

Niño: No.

Entrevistadora: ¿Por qué?

Niño: Porque ellos me molestan siempre por puro que estoy quemado.

Entrevistadora: $Y$ ¿Tú respetas a los demás?

Niño: Si ellos me molestan yo también los molesto”.

(Caso 2, Entrevista $\mathrm{N}^{\circ}$ 6).

El que los niños/as se traten de esta manera al estar en grupo resulta ser un tema relevante en el desarrollo de redes vinculares que no sólo consoliden sus vínculos con sus grupos pequeños de pertenencia, "intra-grupo", sino que desarrollen capacidades para establecer relaciones puentes inter-grupos. Los niños desarrollan su identidad a través de como se miran, junto a lo que el resto les hace ver de ellos, en este sentido se puede ver que en los registros existen focos de exceso de poder de parte de algunos niños/as hacia otros que se muestran más débiles y sumisos frente a esto. El mal trato que emerge que se traduce en descalificaciones, exclusiones, agresiones verbales o físicas, que provocan un "mal-estar" a diferencia del agrado que se siente en el bien-estar de sentirse valorado, querido, integrado y reconocido. En las escuelas observadas, el buen trato se da solo si existe la condición de previa amistad, cariño, afecto y lazos entre los pares.

"Profesor: ¿Qué pasa?

Niño 1: El Joshua le colocó el pie a la Virginia y se cayó.

Profesor: "Eeeeeee, Joshua, yo creo que ella necesita una disculpa, vaya para allá y le pide una disculpa.

Joshua: Se acerca a la niña, la mira a la cara y le dice disculpa.

(La niña deja de llorar, sus compañeros le ayudan a levantarse, le sacuden la ropa y se integran a la actividad que sigue)”.

(Caso 4, Registro № 5).

Como se puede ver en este último registro, el discurso docente no es castigador o autoritario, "yo creo que ella necesita una disculpa..."., luego trata al agresor de "usted" 
y le incita a que resuelva el error cometido, esta acción tan simple, no lo es necesariamente, pues hace tomar conciencia al agresor del daño que ha cometido y luego "hacer algo para enmendarlo", el problema sucede cuando la acción agresora se invisibiliza, lo anormal se vuelve "normal" y los docentes hacen como "si nada pasa" ante el cansancio por la repetición de estas conductas.

3.1.3.1. Discriminación por estética. En los distintos casos encontramos que los niños discriminan a los que no cumplen con las características socialmente atribuidas a la belleza. Muchas veces los niños y niñas se dejan influenciar por los prototipos de belleza entregados tanto por la televisión como también por la escuela, la familia y la sociedad en general, los cuales en la mayoría de las ocasiones no coinciden con las características del pueblo chileno. Ésta es una problemática que afecta la red vincular al discriminar a una persona por su aspecto físico. La experiencia en ser "diferente" a la "norma", afecta en la médula de los derechos "humanos" y de ciudadanos, aspectos tales como: ser más bajo, más gordo, más moreno, el tener un corte de pelo que no está a la moda, excluye de lo "común" al sujeto. Pues al parecer lo común en cuanto a representación simbólica observada conductualmente, lo ha configurado el mercado canalizado por los mass media.

Alumno: Oye Angélica, mejor ándate pa la última fila

Alumna: ¿Por qué po' si la profe me puso acá?

Alumno: Porque con tu cara de poto, tení que estar atrás (ríe)”.

(Caso 1, Registro No 3).

(El niño se saca el gorro).

Niña: Te cortaste el pelo, te vei más feo.

(El niño la mira, agacha la cabeza y no dice nada, se produce un silencio).

Entrevistadora: ¿Por qué dices que se feo?, esta lindo tu corte de pelo, te ves bien”

Niña: Pero si se ve feo

Entrevistadora: $Y$ si yo te dijera que te ves fea con ese moño ¿cómo te sentirías tú?

Niña: Mentira yo sé que soy bonita.

Entrevistadora: Pero igual, acá no hay ningún niño que sea feo, así que tu no le vas a decir más eso porque el se debe sentir mal”.

(Caso 3, Registro $\mathrm{N}^{\mathrm{o}}$ 14).

Entrevistadora: Ahora dime ¿cuál es el lugar que menos te gusta de la escuela?

Niña: Mmm..., el lugar que menos me gusta... la cancha de cemento.

Entrevistadora: ¿Por qué?

Niña: Porque ahí... mmm...... andan todos los niños de mi curso y me molestan.

Entrevistadora: ¿Qué te dicen?

Niña: Ehhh, no me empiezan a decir que soy negra y gorda y me empiezan a molestar. Me dicen negra si".

(Caso 2, Foto-memoria $\mathrm{N}^{\mathrm{o}}$ 4).

Durante la recogida de datos, todos los registros relacionados con estética y belleza, siguen esta dinámica de descalificación y de desvaloración que se arropa de características 
físicas que no concuerdan con el patrón de belleza validado por el poder dominante, y que se corresponde al fenotipo aria, hombre/mujer. En el análisis de los discursos de las entrevistas con el fin de indagar en las temáticas específicas de estética, las respuestas dadas por los niños referente al tema no dejan de sorprender, pues el discurso entregado por ellos es totalmente contradictorio con relación a lo que se observa. Ellos señalan encontrar bellas a las personas con las cuales tienen alguna relación de tipo afectiva y no hacen referencia a la apariencia física, por ejemplo:

Entrevistadora: Tú ¿A quién encuentras bonito, bello, lindo?

Niña: A mi hermana y a mi otra hermana.

Entrevistadora: Ya ¿y por qué las encuentras lindas?

Niña: Porque me hacen cariño y me tratan bien y me dan besos”.

(Caso 3, Entrevista $\mathrm{N}^{\circ}$ 1).

En la mayoría de los casos, estas manifestaciones de discriminación se dan en el patio del colegio, durante el recreo, donde por lo general no hay ningún docente que pueda mediar para que estas situaciones se desaprendan y aprender a vivir en común. Muchas veces los profesores/as presencian escenas de discriminación y no hacen nada al respecto. Al no hacer nada por revertir estas prácticas, están entregando indirectamente a los niños y niñas el mensaje de que esto está bien y es permitido hacerlo. Se ha automatizado tanto la vida escolar, que pareciera que el recreo no existe como espacio de enseñanza de responsabilidad docente, sólo el aula como espacio tradicionalmente estructurado y encasillado por canales que transitan fuera de la vida cotidiana.

3.1.3.2. Discriminación por género. El concepto de género, es un término complejo de comprender ya que se tiende a confundirlo, relacionarlo e incluso a significarlo de inmediato con el de sexo. "La palabra género se refiere a los aspectos sociales y culturales atribuidos a la distinción biológica entre los hombres y las mujeres. El género es un atributo aprendido y no una determinación biológica. En otras palabras, aunque se nazca de sexo masculino o femenino, uno aprende a ser hombre o mujer". (OPS). El concepto de género es un concepto aprendido y construido por cada sociedad para sus hombres y mujeres. Esta construcción comienza en las familias y el hogar desde el momento en el que el niño/a nace, e incluso antes, pero se agudiza principalmente en las escuelas, donde niños y niñas comparten la mayor parte del tiempo. En este lugar los niños se empiezan a formar como hombres y las niñas como mujeres, discriminándose por las acciones que "debe" realizar cada uno. En los centros educativos investigados se encontró gran cantidad de registros referidos a este tema.

"Niño 1: Cacha al Kevin le gana una mujer, es niñita, es niñita.

Grupo de niños: jajajaja, es niñita.

Niño 2: ¿Cómo te puede ganar una mujer? Si las mujeres no saben jugar a las bolitas.

Niño 3 : Es terrible de buena, mira juega con ella, juega súper bien”.

(Caso 4, Reg. No 2). 
"Apoderada: Hola tía, buenas tardes.

Auxiliar: Hola, ahí viene la María Ignacia, espere.

Apoderada: Uuuy la niñita ésta, mira como anda tirándose al suelo. (Grita) ¡María Ignacia, ven, vamos!

Auxiliar: Ya pue María Ignacia, cómo es eso de andar tirándose al suelo. Que feo. Se ve amachotada".

(Caso 1, Registro No 10).

Según las cifras, las mujeres cada vez están tomando más participación en la administración de los hogares y en los puestos de trabajos. Sin embargo esta nueva realidad no se integra al currículum: ¿por qué se les enseña a los niños y niñas que el hombre trabaja y la mujer permanece en casa?, ¿por qué sigue siendo la mujer el sexo débil y el hombre el fuerte? Es extraño, pero los niños/as siguen manifestando en sus acciones que es el hombre el del sexo fuerte y responsable del bienestar de la familia, aunque la realidad no sea siempre así.

Entrevistadora: Ya ¿Qué crees que pueden hacer los hombres?

Niño: Heee puede hacer... puede trabajar”.

(Caso 3, Entrevista $\mathrm{N}^{\mathrm{o}}$ 1).

Entrevistadora: ¿Qué te gusta de ser hombre?

Niño: Porque puedo jugar a la pelota corro más rápido y no se po'.

(Caso 2, Entrevista $N^{o}$ 6).

Entrevistadora: ¿Qué te gusta de ser hombre?

Niños: Que tienen fuerza, tienen más ventajas.

(Caso 2, Entrevista $\mathrm{N}^{\circ}$ 7).

Una de las preguntas de la entrevista, se relacionaba con lo que los niños y niñas creían que no pueden o deben hacer un hombre-mujer en la escuela y hubo una niña que respondió:

"Las niñas deben hacer cosas femeninas como maquillarse, hacer pijamadas y jugar a las muñecas, mientras con los hombres deben hacer cosas masculina como jugar fútbol, a la pelea y a las figuras de acción”.

(Caso $\left.\mathrm{N}^{\mathrm{O}} 4\right)$.

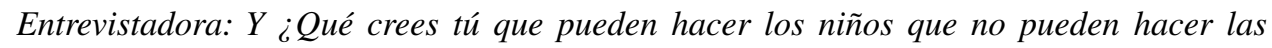
niñas?

Niño: Pelear.

Niño: Sí y jugar fútbol y jugamos a las peleas.

Entrevistadora: ¿Y qué cosas no pueden hacer los hombres? Los niños de tu edad.

Niño: No pueden pintarse las uñas y no ponerse ruch y no andar con botas. 
Entrevistadora: No andar con botas y ¿Qué te gusta a ti de ser niño?

Niño: ¿Lo que más me gusta? Pelear”.

(Caso 3, Entrevista $\mathrm{N}^{\circ} 4$ ).

Los niños y niñas diferencian ciertas acciones e incluso clasifican juegos "para hombre" o "para mujeres" marginando a unos de los otros, lo que probablemente se podría catalogar en ciertas oportunidades desigual, haciendo que niños y niñas crezcan con sentimientos de injusticia, represiones respecto a la imposición que no "pueden" jugar a ciertos juegos ya que socialmente está establecido lo contrario. Esto se observa en el registro anteriormente citado, donde a una niña se le restringe la posibilidad de continuar jugando libremente por la docente que la califica de "hamachotá". Por otra parte, el levantamiento de esta categoría se ve justificado por otra respuesta obtenida de la misma entrevista anterior en una pregunta referida al respeto entre los compañeros/as dentro de la escuela. La niña señala al respecto que: "Niña: Los hombres se pueden defender a golpe, las mujeres no, porque no pelean”. (Caso 1, Entrevista 4). En esta respuesta se observa otro tipo de discriminación en relación al género entre hombres y mujeres. Ellos pueden defenderse a golpes, legitimando la violencia física, mientras que ellas no pueden, sólo porque son mujeres. Llama la atención esta respuesta ya que al ocurrir situaciones así dentro de la escuela, las niñas y los niños configurarán un valor de respeto y validación de la violencia, diferente para ambos. Los niños buscarán ser respetados mediante golpes mientras que las niñas tendrán que hacerlo de otra manera.

En el caso del caso de estudio del colegio privado, confesional y particular pagado, la discriminación de género se expresa como imagen de mujer cristiana conformada por rasgos tales como; responsable, serena, dispuesta a soportar todo. Vale decir, la discriminación de violencia es disfrazada por la renuncia, la tolerancia, la paciencia y el autocontrol de la violencia. Así la vivencia de ciudadanía en la escuela requiere de una mirada reflexiva y práctica de: ciudadanía, educación y género, como lo desarrolla Arnot (2009).

3.1.4. Relación con el espacio físico y sentido de pertenencia. La relación, espacio físico y ciudadanía, engloba al sentido de pertenencia a un "terruño". Sentirse parte de un lugar, sentir que el lugar donde se está, es propio, resulta fundamental a la hora de hablar de cohesión social y formación ciudadana, ya que si una persona se siente parte de un lugar, lo siente propio, actúa en él, haciendo cambios, tomando responsabilidades frente a él y teniendo derechos también. Al definir el significado del sentido de pertenencia, se puede decir que, es el apego que tiene una persona o un grupo de individuos, hacia alguna institución.

Si se considera el lugar físico como otro lenguaje que los sujetos otorgan al "estar en común" es preciso señalar que los niños y niñas más pequeños requieren de espacios que aseguren una cierta seguridad de protección para "estar solos/as", tomándose un tiempo para sí mismo y para disfrutar de momentos de tranquilidad, sin necesidad de realizar una interacción social. Sin embargo, el espacio en cuanto a lenguaje de pertenencia en lo social, requiere de la condición de juego y libertad para adherir a un lugar con ciertos 
privilegios. Este proceso continuo promueve momentos beneficiosos para la configuración de "lo común", por lo que en algunos casos varía según los niveles y edades que los grupos representen. A medida que avanzan en edad, las normas se internalizan, lo que hace que los niños/as busquen espacios donde aquellas no se puedan ejercer, por un descontento, considerándolas en algunos casos injustas. Si tomamos en cuenta que los docentes del establecimiento consideran la libertad como una acción de pérdida del control de las normas, por lo que solo dejan pequeños espacios con libertad de acción, este sentido de pertenencia se pierde. Por motivos de ausencia discursiva abstracta en el lenguaje en niños y niñas pequeños/as, trabajamos recogiendo información con "fotosmemorias", es decir, los más pequeños "sacaban una foto" al sitio de mayor agrado y menos gusto por permanecer allí. Esta asociación simbólica con el espacio está relacionada con la sensación de "seguridad" afecto y libertad que le otorga el lugar.

3.2. En la gran matriz de “lo común”. Participación y Democracia, Gobernabilidad; Control normativo; Idea de un nosotros/as.

\subsubsection{Participación y Democracia}

Esta categoría surge con los registros de observación intra-aula, entrevistas y algunos análisis de documentos. En dos de las escuelas públicas junto a la escuela rural de la región de Viña del Mar, se observa una construcción de consenso ante las normas que ordenarán la convivencia de la escuela, destacando que en la escuela pública urbana, esto se enfatiza en el sector parvulario y tiende a desaparecer a medida que avanza el tramo evolutivo escolar, paradójicamente. Sin embargo, en los cinco casos restantes, los estudiantes no deciden casi nada, ni el turno de habla, lugares de asiento, contenidos, actividades, espacio, tiempo escolar. En siete de los casos observados, la directiva es escogida por el docente, ante el estereotipo configurado de "buen alumno o buena alumna". En dos casos, el docente escoge una terna, y los niños y niñas eligen ante esta propuesta a sus líderes.

Podríamos caer en el supuesto desde la psicología cognitiva según los estadios de desarrollo que desde el pensamiento concreto, es difícil imaginar a un niño de cuatro años, aspectos abstractos éticos y valóricos relacionados con el espacio en común, sin embargo los avances demostrados por Dalberg, Pence, Moss, nos hablan de un sujeto niño/a con potencialidades que superan la lógica estratificada de los estadios cognitivos. Por otro lado, evidencias de teoría cognitiva aportada por Kincheloe; Steinberg y Villaverde sumado a evidencia empírica del proyecto educativo Italiano Reggio Emilia, nos muestran a un sujeto niño/a constructor de relaciones sociales y activo ciudadano de su quehacer social y personal. También nuestros datos de los estudios de caso, nos aportan información de un sujeto niño/a que desea colaborar, decidir, discutir las normas para su consenso, argumentar y sentirse protagonista de su hacer escolar. El espacio escolar tiene instalado un currículum docente-céntrico, normativo, directivo, impositivo con estrategias que no permiten que los estudiantes decidan, haciendo de la forma de relacionarse, una relación asimétrica, impositiva, de vigilancia, poder y control, ausente de comunicación, mediatizada por el castigo. 
En las salas de clases, las prácticas democráticas son escasas, pues no se atienden diferencias individuales, no se fomentan valores tales como la justicia, la igualdad, la solidaridad, el respeto o la aceptación del otro distinto. La Escuela más que ser un espacio democratizador es un espacio de vigilancia, control y castigo.

"Profesor: ¿Quién dijo que tocaran? Cuando yo diga, cuando ¡yo diga!, ¿ya? Cuando yo diga... vamos a partir por fila. Ya, esta fila primero".

(Caso 3, Registro $\mathrm{N}^{\mathrm{o}} 34$ ).

\subsubsection{Control Normativo}

Se evidencia como el centro educativo establece normas para todos los niveles, en horarios, normas de patio, uniformes, etc. y la educadora o docente como el agente regulador de normas dentro de la sala, en la que prescribe los ejes sustantivos éticos de lo "correcto" e "incorrecto" a veces sin sentido para los niños y niñas y por supuesto sin participación. Otro punto importante es la libreta de comunicaciones, el cual es un instrumento que toma importancia desde primero básico, el cual es considerado como elemento castigador desde segundo hasta cuarto básico, solamente en primero no han tomado conciencia de la función que cumple, por lo que aun hacen referencia de que su uso se vincula a "buena o mala la comunicación".

Ante la pregunta de si el establecimiento presenta contextos y situaciones en las cuales el estudiante puede elegir, ellos responde que no, y que solo es posible hacerlo en el recreo:

“NNo!.... (sólo) cuando estamos en el recreo y elegimos los juegos”.

(Caso 8, grupo focal).

"A veces nos anotan por llegar atrasados, porque una vez nos anotaron porque llegamos tarde a gimnasia con un compañero, y la tía no nos dejo entrar, y tuvimos que ir donde el tío Gustavo para que nos diera un pase y llegamos y la tía nos anotó porque habíamos llegado 10 minutos tarde, y habíamos llegado 1 minuto tarde".

(Caso 8, grupo focal).

En general en todos los casos, que suman ocho escuelas, el cumplimiento de normas como plataforma común, se percibe como un sin sentido por los estudiantes y son vivenciados como una contradicción con el sentido común que expresan niños y niñas, con los criterios que emergen de sus lógicas reflexivas. Se puede decir que el control normativo en sus múltiples formas tiende a debilitar el sentido de pertenencia en los grupos estudiados, pese a la rica actividad social que se propicia en el establecimiento. Se observa una subjetividad que demanda espacios de expresión y que los recibe dentro del establecimiento pero que es acogida por las pautas de acción que se desarrollan entre los docentes desde una aproximación maternal/paternal, mediatizada por el afecto "controlador" que es reforzada por la identidad de familia, con lo que se identifican algunos centros. 
Los dispositivos de control actúan fortaleciendo dicha experiencia a través de la libreta de comunicaciones asociada a la información de referencia negativa y castigo de los padres; el uso de diseminación del control involucrando positivamente a los propios compañeros-aquellos que forman parte de la convivencia grata, quienes se transforman en controladores efectivos de las tareas (se presentan como una acción de responsabilidad ante el grupo que suma al control del profesor y el inspector), llegando hasta mensajes-"carteles" sensibilizadores de la buena conducta y el orden dispuestos en las salas de clases.

\subsubsection{Prestigio social}

Esta categoría se levanta con diferentes significados según la dependencia administrativa de los centros: En el colegio particular pagado confesional y subvencionados, en el que también son confesionales, esta categoría se configura desde la "identificación" de un estereotipo comportamental vinculado a la obediencia, cumplimiento de normas, buen trato a compañeros/compañeras y acato ante las directrices docentes. Este patrón y su vivencia, permiten al sujeto gozar de "prestigio social". Esta categoría presenta una evolución desde $1^{\circ}$ nivel de transición al $4^{\circ}$ básico, en la que se distinguen patrones comportamentales por sexo y a medida que avanzan en el tramo evolutivo, se adhieren a este patrón normas y valores morales, tales como solidaridad, respeto a Dios, normas y deberes, los cuales son seguidos y difundidos por los lideres que sirven de ejemplo para los demás niños del grupo. Sin embargo este comportamiento moral de base religiosa no se mantiene en cuarto año, existiendo solo un liderazgo que se ordena según los niños que representan los mayores intereses del grupo curso, de acuerdo a los intereses y comportamientos comunes.

En los colegios municipales, públicos el prestigio social lo configura el patrón o estereotipo de "resistencia" al poder oficial. Vale decir, el que goza de prestigio social, en su grupo de pares, es que se rebela a la norma, el que se atreve en valentía romper el mandato oficial. Esta legitimidad que hace el grupo a su líder, se da por grados según tramo evolutivo, crece en la medida que se avanza de nivel en la configuración del prestigio social dado por el grupo de pares.Si bien, en todos los centros la categoría que se configura desde de prestigio social, cobra mayor fuerza desde el grupo de pares a medida que avanza el ciclo evolutivo, en los colegios subvencionados y particular pagado, esta legitimación de pares, es más lenta y hasta cuarto básico hay un fuerte énfasis de prestigio social, otorgado por la configuración que hace el docente de este estereotipo apegado a la obediencia del cumplimiento de la norma establecida por el poder oficial.

También se configuran estereotipos sexistas en el prestigio social diferenciado por nivel económico. Cabe destacar que a muy temprana edad, en un caso de estudio municipalizado, el prestigio social, es configurado por el grupo de pares como resistencia al estereotipo configurado por la norma establecida, es el caso de una niña de $1^{\circ}$ básico que resiste todas las normas establecidas y contradice estereotipos estéticos conservadores, a diferencia del colegio particular pagado confesional en que el prestigio social femenino, los configura la imagen de la virgen, madre abnegada, en un marco burgués femenino conservador. 
Esto podría explicar o predecir, dificultades en la red de cohesión social vincular puente, pues las configuraciones de prestigio social obedecen a estereotipos muy disímiles en la aceptación y reconocimiento del grupo de pares a quien goza de aquel prestigio en el liderazgo del grupo. Estas representaciones simbólicas de prestigio social en la infancia, son preocupantes a la hora de configurar el imaginario de un tejido social que tiene por objetivo una cohesión social puente íntergrupos.

\subsubsection{Sobre la idea de un nosotros}

Los colegios subvencionados y particular se caracterizan por dos fuerzas contrapuestas; por un lado se observa una gran satisfacción de los estudiantes en relación a sentirse integrados entre si y con los docentes, ello debido al estilo de relación que éstos propician en sus espacios de convivencia; trato directo, personal, fundado en una paciencia maternal-paternal y en la actitud de escuchar a los estudiantes. A ello se agrega una auto-percepción de un nosotros vinculada al grupo de referencia (curso) que se sostiene en el propio cuidado y la ayuda, en los grupos de tercero y cuarto básico. No obstante, los propios estudiantes evidencian la disonancia en relación a sentir en propiedad la pertenencia al establecimiento, en tanto ésta se debilita y es identificada como propia sólo de aquellos que detentan la autoridad y el poder lo que enuncia una pertenencia débil en términos participativos en la definición y ejercicio de las normas. Sin discutir la necesidad de su existencia para la convivencia, convendría reflexionar sobre el modo en que ésta encarna o se percibe por los estudiantes quienes se evidencian altamente sensibles al castigo y la anotación. En los colegios públicos, la percepción de pertenencia es heterogénea, sienten que el colegio le pertenece al Director/a, pero en la mayoría de los casos, sienten propio el espacio de la escuela, aunque se constate formas de relación entre docentes y estudiantes y entre pares de "mal trato".

Existe un proceso evolutivo que va permitiendo que el niño/a de a poco se vaya integrando en la comunidad escolar y en su grupo de pares, lo que va permitiendo que se cree una relación de apego y a la vez de interdependencia entre ellos. Esto queda en evidencia al comparar las relaciones existentes entre los niños y niñas de Kinder y de cuarto básico, ya que, en el primer curso los niños se encuentran en una fase de adaptación al mundo escolar al cual la mayoría esta recién ingresando y por tanto están en un proceso de conocer nuevas rutinas, normas y formas de relación nuevas que hacen que la pertenencia este dada desde un sentido de lograr una integración en el grupo que se deriva en acciones de autocuidado que pueden deberse a una identificación con el proceso que vive el otro, y por tanto sus esfuerzos estarían avocados a hacer sentir bien a este otro que esta viviendo el mismo momento que nosotros. Sin embargo en $4^{\circ}$ básico los niños y niñas han ido compartiendo años y momentos que han permitido ir creando lazos y le han ido dando un nuevo sentido a la pertenencia ya que en este momento no se trata de ayudar a integrar a otro dentro del curso si no más bien de fortalecer los lazos que se han producido durante todo el tiempo compartido y que han creado una sensación de grupo curso, o sea, una conciencia colectiva de pertenecer a un grupo que los lleva a cuidarse y retroalimentarse mutuamente, no por identificación sino porque 
de esta manera se logra mantener unido al grupo curso que les brinda la seguridad e la pertenencia que se necesita.

Sin embargo, el sentido de pertenencia es distinto en los diferentes centros. En los colegios privados y subvencionados, el sentido de pertenencia está asociado al sentimiento de seguridad y confort afectivo, vale decir, asociado a la sensación de integración que provoca la docente de cada asignatura, ya que por lo observado se constató que cuando los docentes no mantienen canales de comunicación fluidos con los niños/as estos se resienten demostrando menor integración grupal, y por tanto menor sentido de pertenencia al grupo, contrariamente a lo que ocurre cuando los docentes si se preocupan de crear un buen lazo con sus alumnos/as.

Visto de esta forma, si los individuos no logran forjar una idea de un "nosotros", difícilmente lograrán desarrollar valores ciudadanos, debido a que el trabajo ciudadano no es una tarea individual, sino un ejercicio social. Sin embargo, en muchas situaciones se pudieron ver dinámicas que sí aluden a esta dinámica, como por ejemplo, en juegos de patio, en dónde los niños y las niñas al estar fuera de la supervisión y autoritarismo del docente, practican valores ciudadanos correspondientes al ámbito del espacio común, como el respeto, la tolerancia, la capacidad organizativa, la solidaridad. Dadas estas dos contraposiciones, se puede concluir, que la dificultad que poseen niños y niñas para construir el concepto del "nosotros", guarda más relación con que el dominio de la Escuela, no es suyo, lo albergan los docentes y, en general, los adultos en nuestra sociedad. Es por esta razón que al contestar la pregunta de “¿Sientes que el colegio es tuyo?”, muchos respondieron que no, que es de otros, o porque mandan otros, pues no poseen sentido de pertenencia hacia este espacio. De esta forma, ese "otros" correspondería a "Los adultos", pues los niños y las niñas cuando se encuentran solos, logran construir normas, establecer un objetivo común y cohesionarse.

\section{PALABRAS FINALES A MODO DE CIERRE}

Lo común y la sociedad se presentan como categorías debilitadas tanto desde la experiencia y significación de los estudiantes, (representaciones simbólicas) así como de los docentes. Ambos coinciden en sus acciones y discursos una constitución de lo social en el cual ellos actúan de forma pasiva ante una regulación externa normativa regulada por tendencias neoliberales de sustitución de lo público por el mercado. Los estudiantes, reflejan representaciones simbólicas configuradas desde los medios de comunicación que aluden a: estereotipos sexistas, estereotipos estéticos, relaciones de exclusión, discriminación, inseguridad y desconfianza; "la sociedad esta mal", asociando el mundo social diverso con la violencia que debe ser controlada (cárceles para los delincuentes), para asegurar la felicidad, vale decir el panóptico que se vive en la escuela trasladado al orden social-estatal. En suma, se observa un déficit de lo común-social en los niños/ niñas mediado por la experiencia disponible dada por la procedencia de clase social y la edad y por la mediación débil realizada por los docentes. Ellos mismos manifiestan esta debilidad al mismo tiempo que una debilidad institucional en la entidad que no ha tenido en el último tiempo una política clara y sostenida evaluable por lo cual se evidencia que los valores morales, se pierden al comenzar los niños la adolescencia. 
Las representaciones simbólicas que se configuran en torno al "prestigio social" avizoran un problema serio de fragmentación social por clase, en lo más profundo de la identidad que se valora como "prestigiosa" que se observa contradictoria según colegio de procedencia. El tema de cohesión social en sus dimensiones "puente" es fundamental si se quiere crecer como país en desarrollo humano y capital social. Sin embargo la estructura educacional del país posee una plataforma administrativa escolar que segrega en nichos sociales de clase, lo que implica desde los primeros años distintas configuraciones en las representaciones de lo común, la identidad, la forma de tratarse, el prestigio social, los sentidos de pertenencia y por ende el ideario común.

En el contexto de estas reflexiones emergentes, producto de análisis interpretativo del discurso y del hacer, se levantan nuevas preguntas e hipótesis que ameritan la necesidad por re-inventar el sentido de la Escuela, que implique mirar más allá a la mera reproducción de aprendizajes descontextualizados del mundo social y personal, político y económico. Esto conlleva a un cambio en la didáctica del currículum, que sustentado en "mapas de progreso" no necesariamente se orientan a la identidad personal y colectiva, es decir, al trabajo intencionado con la identidad ciudadana. En este sentido, el foco debiera iniciarse en el trabajo de equipo entre docentes, administrativos y estudiantes, en donde prime, la identidad local de la común-unidad, sustentada en la solidaridad, la tolerancia, el respeto y la libertad, valores básicos para educar en democracia.

Para esto, es necesario incorporar a los currícula de formación docente, docentes en ejercicio, y especialmente en las políticas públicas de nuestro Estado-nación, la congruencia de lo aquí expuesto, como factor clave para la educación de los valores ciudadanos y la transmisión de éstos en la escuela. Los docentes debieran conocer, comprender y vivir las implicancias de un proyecto ético político, como también la toma de conciencia sobre la importancia y repercusión social de la escuela en la formación ciudadana y la construcción de identidad, como base para la cohesión social de un pueblo. No sirve que sólo un docente o sólo una Escuela, sea él o la que domine esta materia conceptual, debe existir una unidad dentro del colegiado de profesores en donde se promulguen estas prácticas dentro del sistema educativo, como una cultura naciente que logre transformar realmente la forma de "mirarse" y por ende construirse como persona social-personal. El tema de la homogenización, no deja de ser menor en la forma de configurar el itinerario cotidiano de escuelas muy disímiles en TODO, sin embargo a simple vista se observa un "habitus" estructurante y estructurado por un "automatismo" mecanicista que arropa la escuela de horarios, normas, estatutos, reglas y especialmente mediciones estandarizadas en que lo desigual se disfraza de lo igual y por tanto perversamente y/o profundamente inequitativo como sistema social.

\section{BIBLIOGRAFIA}

Amartya S. (2007). "Identidad y violencia". Editorial Katz. Argentina.

Angulo, F. J., Connell, R. W., Goodman, J., Kemmis, S., McLaren, P., Miller, J. N., Paraskeva, J. (2008). "Democracia, Educación y Participación en las Instituciones Educativas", $1^{a}$ edición Morón, Sevilla - España. 
Alvarado, Bustamante, Rubio y Tapia (2002). "Evidencia de Contradicciones y paradojas en la Educación Parvularia: Un estudio cualitativo". Tesis para optar al grado de licenciatura en educación Universidad católica de Valparaíso, Escuela de Pedagogía. Biblioteca Mayor.

Aple M.W. y Beane, J.A. (1997). “Escuelas Democráticas". Reimpresión 2000. Editorial Morata, España.

Argot, M. (2009). “Coeducando para una ciudadanía en igualdad”. Editorial Morata, Madrid, España.

Balibar, E. (2005). "Violencias, Identidades y Civilidad. Para una cultura política y global”. Editorial Gedisa, S.A, Barcelona.

Bartolomé Pina, M. (2002). "Identidad y Ciudadanía. Un reto a la educación intercultural". Narcea, S.A de Ediciones, Madrid - España.

Bauman, Z. (2006). "COMUNIDAD. En busca de seguridad en un mundo hostil". Siglo XXI Editores, $1^{a}$ edición. Madrid, España.

Bauman, Z. (2007). "Miedo Líquido". Editorial Paidós. Argentina.

Bauman, Z. (2006). "Modernidad Líquida". Fondo de Cultura Económica Argentina.

Bauman, Z. (2007). "Vida de Consumo". Fondo de Cultura Económica. Argentina.

Bauman, Z. (2005). revista $n^{\circ} 206$ "Anthropos" teoría social y ambivalencia". España.

Bourdieu, P. (1999) "La misère du monde" Paris. Ed. Seuil, 1994. En Sur Ediciones: "Proposiciones".

Bernstein, B. (1993). "La estructura del discurso pedagógico”. Segunda edición 1994. Editorial Morata. España.

García Canclini, N. (2004). "Diferentes, Desiguales y Desconectados". Editorial Gedisa.S.A. Barcelona, España.

CEPAL. VVAAA. "Cohesión social en América Latina y el Caribe: Una revisión perentoria de algunas dimensiones. Editores Ana Sojo y Andras Uthoff. En este documento se analizan diferentes autores. entre ellos. Hopenhayn, 2007. José Luis Machinea, Peter Abrahamson: Sonia Draibe y Manuel Riesco, Hans Jürgen Rösner, Juan Carlos Feres y Carlos Vergara: Eduardo Amadeo, Miguel Székely, Leonardo Garnier, Fernando Filgueira, Andras Uthoff, Adolfo Rodríguez Herrera, Oscar Cetrángolo, Juan Carlos Gómez-Sabaini, José Roberto Afonso, Juan Alberto Fuentes K.

De Sousa Santos, B. (2005). "El Milenio Huérfano. Ensayos para una nueva cultura política". Editorial Trotta, Madrid, España.

Cobo, R. (2008. Educar en la ciudadanía. Perspectivas Feministas". Los Libros de la Catarata, Madrid, España.

Connell, R.W. (1997). "Escuelas y justicia social”. Reimpresión 1999 por Morata, España.

Cox, C. (2004). "Educación y Cohesión Social en Latinoamérica: Signos Ambivalentes", Comisión de Formación Ciudadana, Chile.

Cox, C. (2008). Educación y cohesión social en Latinoamérica: Signos ambivalentes. Cristián Cox: Redes, estado y mercados. Soportes de la cohesión social Latinoamericana. Editor Eugenio Tironi. Editores Uqbar. Santiago. (417 pp.). El nombre del capítulo es: Las reformas educativas y su impacto sobre la cohesión social en América Latina (Capítulo 5, pp. 275-321).

Cullen, C. (1999). "Autonomía Moral, participación democrática y cuidado del otro" Ediciones Novedades Educativas, $2^{\circ}$ edición, Buenos Aires, Argentina.

Dalberg, C., Moss, P. y Pence, A. (2005). "Mas allá de la Educación Infantil”. Editorial Graó. España.

Delval, J. (2000). "Aprender en la vida y en la escuela". Editorial Morata. España.

Delgado, J. M. y Gutiérrez, J. (1994). "Métodos y Técnicas cualitativas de investigación en Ciencias sociales". Editorial Síntesis Psicología.

Fernández Enguita, M. (1993). "La profesión Docente y la comunidad escolar: Crónica de un desencuentro". Segunda edición, 1995. Ediciones Morata. España. 
Fernández Lira, C., Fernández Lira, P. y Alegre Zahonero, L. (2007). "Educación para la Ciudadanía. Democracia, Capitalismo y Estado de Derecho", Edisiones Akal, Madrid.

Giroux, H. (2001). Cultura, política y práctica educativa. Editorial Graó, Biblioteca de Aula. España.

Goetz, J. P. y Lecompte, M.D. (1988). Etnografía y diseño cualitativo en investigación educativa. Editorial Morata.

Gil Flores, J. (2000). "Análisis de datos cualitativos". Documento programa de doctorado: Evaluación, mejora y calidad en la educación Superior. Universidad de Cádiz.

Gimeno Sacristán, J. (2001). "Educar y convivir en la cultura global”. Edit. Morata. Madrid, España.

Gimeno Sacristán, J. (2000). "La educación obligatoria: su sentido educativo y social”. Ediciones Morata, Madrid.

Hopenhayn, M. (2004). "Cohesión social, una perspectiva en proceso de elaboración".

Hun, C. y Maldonado, L. (2003). Demócratas y nostálgicos del antiguo régimen. Los apoyos de la democracia en Chile, Santiago de Chile, CERC, 2003, www.cerc.cl

Kicheloe, J. L., Steinberg, Sh. R. y Villaverde, L. E. (2004). "Repensar la inteligencia”, Morata S.A., Madrid.

Martínez Rodríguez, J. B. (2005). "Educación para la Ciudadanía”. Editorial Morata, España.

Mires, F. (2001). "Civilidad" teoría política de la postmodernidad". Editorial Trotta. Madrid España.

Ottone, E. (¿AÑO?). Del Desarrollo Social A La Cohesión Social: Algo Más Que Un Giro Semántico En Las Propuestas De La CEPAL. Ponencia preparada en colaboración con Martin Hopenhayn. Presentada en el Ciclo de Conferencias Tribuna de las Economías Latinoamericanas, 27-29 abril, Paris. IEA Civic Education Study database. La información de CIVICA por cada país se encuentra disponible en el siguiente link: http://www.iea.nl/cived_datasets. html?\&no_cache=1\&sword_list][]=civic\&sword_list[]=dat

Pérez Gómez, A.I. (1999). “La cultura escolar en la sociedad neoliberal”. Edición Morata, segunda edición.

Peña, C. (2008): "El concepto de Cohesión social" Capítulo 1 de libro "Redes Estado y Mercados". Soportes de la cohesión social en Latinoamericana", coordinado por Tironi. Editores Uqbar Santiago de Chile.

Peña, C. (2007). Crónica de "El Mercurio", Reportajes D12 "El mal infinito". Domingo 10 de junio 2007.

Peña, C. (2004). Documento MINEDUC, bajo la tutela del ministro de educación Sergio Bitar. MINEDUC-CHILE.

P.N.U.D. Programa de las Naciones Unidas para el Desarrollo 2002: "Desarrollo Humano en Chile".

Redon, S. (¿AÑO?). "La transveraslidad en el currículum” tesis doctoral Universidad de Cadíz España. Regitsrada en la biblioteca de dicha Universidad.

Redon, S. (¿AÑO?). Revista de Cooperación Educativa Española: Monográfico de "ciudadanía". Ciudadanía: Utopías y contradicciones en los procesos de formación del profesorado". Educación para la ciudadanía: formación ética y política ISBN: 1133-0589 Septiembre - Noviembre 2008, $\mathrm{N}^{\circ} 90 \mathrm{http} / / / \mathrm{www}$. cooperacioneducativa.com/catalogo/sumario/sumario_90.htm

Rodríguez, A. (¿AÑO?). "La Educación para la Primera Infancia para Latinoamérica".

Putnam, H., Habermas, J. (2008). "Normas y Valores”, Editorial Trotta S.A., Madrid, España.

Rojas, C. (¿AÑO?). "Reflexiones Sobre la Ciudadanía: Aproximaciones al Caso Chileno".

Stake, R. E. (1998). "Investigación con estudios de caso":Editorial Morata. España.

Sojo, A. y Uthoff, A. (¿AÑO?). "Cohesión Social en América Latina y el Caribe: una revisión perentoria de algunas de sus dimensiones". Comisión Económica para América Latina y el Caribe (CEPAL). 
Tadeu da Silva, T. (2001). "Espacios de Identidad". Editorial Octaedro.

Taylor, S. J. y Bogdan, R. (1994) "Introducción a los métodos cualitativos de investigación". Editorial Paidós. España,

Tironi: (2008) "Redes Estado y Mercados" Soportes de la cohesión social en Latinoamericana", coordinado por Tironi. Editores Uqbar, Santiago de Chile.

Touraine, A. (1998) "Igualdad y diversidad". Fondo de Cultura Económica, Colección Popular, Brasil el 2000.

Touraine, A. (1997). “¿Podremos vivir juntos?”. Segunda reimpresión. Fondo de Cultura Económica. Argentina.

Valenzuela, ¿? (2007). Documento de Trabajo: "Encuesta Latinoamérica de cohesión social", principales resultados: Eduardo Valenzuela 2007.

Valles, M. (1997). “Técnicas cualitativas de investigación social”. Editorial Síntesis Psicología.

Varas, A., Abregú, M., Palacios, M., Lacoste, J.P., Delamaza, G., Fernández, M., Triveli, C., Asencio Hernández, R., Fuentes, C. y Heiss C. (2006). "La Propuesta Ciudadana. Una Relación Sociedad Civil-Estado". Fundación Ford Catalonia Ltda, Santiago, Chile.

Vidal Jiménez. R. (2005). "Educación, poder y mercado: deconstrucción crítica de los efectos disciplinantes de las TIC en la nueva Escuela del Espectáculo". Comunicación, Saúde, Educación.

Vonk, J.H. (2000). El contexto social cambiante de la enseñanza en la Europa occidental. En: Biddle, Good y Goodson, "Internacional Handbook of teacher and teching". Paidós. Barcelona.

Whitty, G. (2000). "Teoría social y política educativa". Ediciones Pomares Corredor, S.A., www.wikipedia.com

www.coe.int, "eroupean strategy for social cohesion". 
